\title{
Male Infertility and Varicocele: An Update
}

\author{
Bhaskarapprakash Ranganath, Sriram Krishnamoorthy* and Natarajan Kumaresan \\ Department of Urology \& Renal transplantation, Sri Ramachandra Institute of Higher Education \& Research, India
}

Submission: June 23, 2020; Published: July 01, 2020

*Corresponding author: Sriram Krishnamoorthy, Department of Urology \& Renal transplantation, Sri Ramachandra Institute of Higher Education \& Research, Chennai, Tamil Nadu, India

\begin{abstract}
Varicocele is the dilatation of the pampiniform plexuses. It is a treatable cause of infertility. The incidence is higher in infertile men, ranging from $35-80 \%$. Although various mechanisms are postulated for the formation of varicocele, the pathological mechanisms by which varicocele causes sperm dysfunction are oxidative stress, testicular hypoperfusion, and heat stress. Various studies have documented venular and testicular architectural changes secondary to varicocele. Varicocele repair in the management of male infertility had been controversial. Recent randomized controlled trials have shown that many of these factors are reversible following varicocele repair and it results in a definitive improvement in sperm DNA fragmentation and semen parameters. Several meta-analyses and RCTs have shown that following varicocele repair, there is a statically significant improvement in both pregnancy rates and live birth rates. Even in the era of assisted reproductive technology, varicocele repair helps to resort to lesser invasive techniques with better pregnancy rates and live birth rates. The outcome of assisted reproductive technology also improves following varicocele repair. This also results in cost-effectiveness in achieving pregnancy. There are many techniques for varicocele repair. A meta-analysis of randomized controlled trials has been done to identify the best technique in terms of semen parameter improvement and post-operative recovery. Most techniques result in similar improvement of semen parameters, but the complication rate is the least with micro- sub inguinal varicocelectomy. The use of intraoperative doppler also helps in the identification of all branches of the testicular artery.
\end{abstract}

Keywords: Varicocele; Oligospermia; Azoospermia; Infertility; Pampiniform plexus

Abbreviations: ROS: Reactive Oxygen Species; ICSI: Intracytoplasmic Sperm Injection; ASRM: American Society of Reproductive medicine; TMSC: Total Motile Sperm Count; CI: Confidence Interval

\section{Introduction}

Infertility is defined by the World Health Organization as the inability to achieve pregnancy within 12 months of unprotected regular intercourse. In couples seeking fertility care, around $50 \%$ have male associated causes. The cause for the defective sperm parameters is idiopathic in 30-40 \% [1]. Varicocele is characterized by abnormal dilatation of pampiniform plexus formed by internal spermatic veins within the spermatic cord. Varicocele is present in $15 \%$ of the general male population, in $35 \%$ of men with primary infertility, and up to $80 \%$ of men with secondary infertility [2]. The association between infertility and varicocele was first reported by Tulloch in 1952, where he documented that varicocelectomy in azoo spermic patients resulted in the return of normal semen parameters postoperatively and even spontaneous pregnancy [3]. Varicocele forms one of the important and a treatable cause.

\section{Pathology and Pathogenesis}

The pampiniform plexus in the spermatic cord contains two bundles of veins, one tightly wrapped around the testicular artery and another in fatty tissue. There are two other plexuses, one around the cremasteric artery and another around the vas deferential artery [4]. The longer drainage pathway and perpendicular insertion of the left spermatic vein into the left renal vein explain the mechanism and preponderance of varicocele on the left side [5]. Valvular dysfunction or absence of valves in the spermatic veins contribute to the formation of varicocele [6], The presence of extensive collaterals with anastomosis of internal and external spermatic veins contributes not only to the varicocele formation but also explains the recurrence after varicocele repair [7]. Varicoceles cause testicular damage resulting in loss of testicular volume and its spermatogenic function. The pathological mechanism of testicular dysfunction secondary to varicocele has been attributed to the increased oxidative stress resulting in sperm DNA damage, local hormonal imbalances, stasis of blood with toxin accumulation, testicular hypoperfusion, and heat stress [8]. The damage by reactive oxygen species is the common final pathway of sperm functional damage. 


\section{Global Journal of Reproductive Medicine}

\section{Oxidative stress}

The normal semen has some amount of reactive oxygen species (ROS) for the reproductive function of sperm as they are required for the various stages of fertilization like capacitation, the digestion of the zona by acrosomal enzyme and sperm oocyte fusion. Elevated ROS found in the semen of varicocele men causes apoptosis of mature spermatozoa, reduced membrane fluidity which has a detrimental effect on the structure of sperm head and midpiece membrane, thus ultimately leading to suboptimal motility and fertilization [9]. Elevated ROS causes sperm DNA fragmentation causing subfertility in men [10].

\section{Heat stress}

Goldstein et al had noticed that there is an increase in scrotal skin surface and intratesticular temperature in men with varicocele. They also noted that even in men with unilateral varicocele, the contralateral intratesticular temperature is raised favoring a "hot rock theory" (If you have 2 rocks in a sack and one is constantly being heated, the other one will become warm as well) [11]. Varicocelectomy reverses the hyperthermia in the scrotum and promotes normal spermatogenesis [12]. Histopathology of the spermatic veins in varicocele have shown alterations in the muscle layers, especially decreased longitudinal smooth muscle layer with the reduced number of nerve fibres and vasa vasorum in its walls, leading to abnormal dilatation of veins [13]. Varicocele leads to a decrease in testosterone production by Leydig cell. Studies have reported a lower testosterone level in men with varicocele when compared to men without it (412.2 vs. $462.6 \mathrm{ng} /$ dl; $\mathrm{P}<0.001$ ) [14].

\section{Effect on Semen Parameters}

Varicocele affects the semen parameters, the earliest parameter being affected is sperm motility (asthenozoospermia), followed by sperm morphology. The severity of these changes depends on the severity of varicocele grade. Sperm count is usually the last parameter to be affected leading to oligozoospermia and in the most severe cases azoospermia [15]. Long-standing varicocele can cause a decrease in testicular size and higher FSH values due to decreased spermatogenesis [16]. The semen volume is usually unaffected despite the changes in other semen parameters [17]. After varicocelectomy, there is an improvement in all semen parameters, more in sperm motility [18]. With the negative impact of varicocele on the testicular function and infertility proved in many studies, the role of varicocele repair in improving fertility must be addressed. The role of varicocele repair had been controversial for a long time. Varicocele repair has shown a definitive improvement in the sperm DNA fragmentation index which has correlated with an increase in pregnancy rates following surgery [10].

\section{Clinical Grading}

Dublin in 1970, classified varicocele into three types [19]. Grade 1 included a palpable varicocele, observed in with Valsalva maneuver in an erect posture. Grade 2 includes varicoceles that are palpable without Valsalva maneuver and grade 3 includes those that are visible through the scrotal skin Ultrasound assessment of the varicocele can be considered in clinically equivocal conditions like a small scrotum, obese patient, patient with a history of prior scrotal surgery [20]. Subclinical varicocele is a condition where the diagnosis is established by an ultrasound study and is not palpable clinically. Meta-analysis shows that varicocele repair in subclinical varicocele does not result in a significant change in semen parameter and pregnancy rates. Hence, an ultrasound study in every patient is not required to diagnose subclinical varicocele [21].

\section{Indications of Varicocele Repair}

Varicocele repair as a treatment for infertility should be considered when most or all the following conditions are fulfilled (American Society of Reproductive medicine (ASRM) guidelines),

a) Palpable varicocele on physical examination of the scrotum.

b) Abnormal semen parameters in a male partner.

c) The couple with infertility documented.

d) Normal female factor or a potentially treatable cause of infertility, when the time to conception is not a concern.

Varicocele treatment is not indicated in patients with normal semen parameters, isolated teratozoospermia, or a subclinical varicocele [22]. In a meta-analysis of 17 studies, it was demonstrated that the sperm concentration, motility, and morphology increased with both microsurgical varicocelectomy and high ligation Varicocelectomy [23].

\section{Azoospermia and Varicocele}

Haydardedeoglu et al analyzed the benefits of varicocele repair in patients with non-obstructive azoospermia prior to intracytoplasmic sperm injection (ICSI) with testicular sperm retrieval (TESE). They concluded that varicocelectomy improved sperm retrieval rates (sperm retrieval rate of $60.81 \%$ and $38.46 \%, \mathrm{P}=<0.01$ ). The clinical pregnancy rate and live birth rate were significantly higher in the repair group when compared to the expectant group $(74.2 \%$ vs $52.3 \%$ and $64.5 \%$ vs $41.5 \%$, respectively, $\mathrm{P}<0.05$ ] [24]. Esteves et al. found that varicocelectomy in men with non-obstructive azoospermia led to the return of sperm in the ejaculate in $43.9 \%$ of patients and was associated with a $13.6 \%$ natural spontaneous pregnancy rate. Besides, they found that correction of varicocelectomy in this group was associated with improved sperm retrieval rates (odds ratio $[\mathrm{OR}] 2.65$, 95\% confidence interval [CI] 1.69-4.14; $\mathrm{p}<.001$ ) [25].

\section{Varicocele in Adolescents}

Management of varicocele in adolescents has been a matter of debate. It is seen as a potential threat to the future fertility 


\section{Global Journal of Reproductive Medicine}

of the individual. The incidence of varicocele in pediatric/ adolescence ranges between 4-35 \%, diagnosed more commonly in late adolescence. The assessment of severity and the need for surgery is determined based on the following parameters; namely testicular consistency, size, asymmetry, and semen analysis in postpubertal boys. Surgical repair is indicated if the testicular size asymmetry is more than $10 \%$. The postoperative follow-up in these boys shows a catch- up growth ranging from $69-86 \%$. In a follow-up study of adolescent varicocelectomies, comparing paternity rates between men who had undergone varicocelectomy to men who were treated conservatively showed a significantly higher paternity rate in the operated group [26].

There are various techniques for varicocele repair. It includes,

1) Open varicocelectomy

a. High/retroperitoneal

b. Inguinal approach

c. Sub inguinal varicocelectomy.

2) Laparoscopic varicocelectomy

3) Microsurgical varicocelectomy.

4) Percutaneous varicocele embolization

The older techniques of high ligation of the spermatic veins by either open or laparoscopic approach did not address the multiple anastomoses between the internal and external spermatic veins that lead to high recurrence rates. The concept of sub inguinal varicocelectomy had a lesser recurrence and complication rates. The use of an operating microscope with better visualization and sparing of lymphatic channels and artery has led to lower hydrocele formation and improvement in fertility indices [27]. The use of intraoperative high frequency doppler has enabled the identification of the testicular artery, even vas deferential artery, and reduces the risk of testicular atrophy with lesser postoperative complications [28]. In a low resource setting, loupe assisted sub inguinal varicocelectomy can be attempted to minimize the postoperative complications [29]. In a meta-analysis of 33 studies, involving over 5000 patients, various current varicocelectomy techniques (surgical and radiological) were analyzed. The primary parameters analyzed were the surgical outcome and changes in semen parameters. The increase in seminal parameters varied from 50 to $80 \%$ in operated patients. The microsurgical sub inguinal surgery had higher pregnancy rates, lower varicocele recurrence, and hydrocele formation with the best outcome and cost-effectiveness in achieving pregnancy. Surgical complications were highest in the laparoscopic technique. The incidence of recurrence of varicocele was more in the radiological procedure when compared with surgical methods (12\% Vs 9.6\%) [30]. In another meta-analysis by Wang et al, comparing ten methods of varicocelectomy, revealed that inguinal and sub inguinal micro-varicocelectomy had the highest pregnancy rates, significant increase in sperm parameters, with low odds of complications [31]. A meta-analysis was conducted to compare open non-microsurgical, laparoscopic, and microsurgical varicocele repair. It included four randomized controlled trials, comprising of 1,015 patients. The study concluded that patients who underwent microsurgery had better pregnancy rate (OR $=1.63,95 \%$ confidence interval $[\mathrm{CI}]: 1.19-2.2$ ) than their counterparts. The postoperative complications like hydrocele were significantly lower after microsurgery than after laparoscopic or open Varicocelectomy [32]. Penson et al had demonstrated the cost-effectiveness of doing varicocele repair in place of immediate IVF [33].

\section{Varicocele and Artificial Reproductive Techniques}

Varicocele repair helps in improving the semen parameters and hence can downgrade the infertility treatment required. In a study, candidates with varicocele were grouped based on their total motile sperm count (TMSC), into 3 arms, candidates for IVF /ICSI (TMSC $<5$ million/ml), candidates for Intrauterine insemination(IUI) (TMSC 5-9 million/mL) and candidates for natural pregnancy try (TMSC > 9 million). Following varicocele repair, $31 \%$ of candidates in Intracytoplasmic sperm injection arm showed improvement in semen parameters allowing treatment downgrading to IUI or natural pregnancy. About $42 \%$ of candidates in IUI arm were shifted to natural pregnancy levels [34]. Studies that assessed the psychosomatic effects have shown that men with varicocele resulting in infertility had more 'negative emotional responses', including a sense of loss and reduced self-esteem than men with female factor infertility or unexplained infertility [35].

\section{Conclusion}

Varicocele is one of the common factors causing male infertility. Because it is a correctable cause of infertility, clinical examination of the male partner to rule out varicocele is the inevitable first step in the evaluation of any infertile couple. The candidates for varicocele repair should be carefully selected as per the indication criteria after thorough counseling. Varicocele repair improves both the aspects of testicular functions namely spermatogenesis and testosterone secretion. Varicocele repair improves the semen parameters resulting in spontaneous pregnancies and improves the assisted reproductive technique's outcomes. Microsurgical sub-inguinal varicocelectomy is the preferred technique of varicocele repair with the least complications reported.

\section{References}

1. A Jungwirth, T Diemer, Z Kopa, C Krausz, S Minhas, et al. (2018) EAU guidelines on male infertility.

2. Alsaikhan B, Alrabeeah K, Delouya G, Zini A (2016) Epidemiology of varicocele. Asian J Androl 18: 179-181.

3. Tulloch WS (1955) Varicocele in subfertility: results of treatment. British Medical Journal 2(4935): 356-358.

4. Ergün S, Bruns T, Soyka A (1997) Angioarchitecture of the human spermatic cord. Cell Tissue Res 288: 391-398. 


\section{Global Journal of Reproductive Medicine}

5. Masson P, Brannigan RE (2014) The varicocele. Urol Clin North Am 41(1): $129-144$

6. Braedel HU, Steffens J, Ziegler M, Polsky MS, Platt ML (1994) A possible ontogenic etiology for idiopathic left varicocele. J Urol. 151(1): 62-66.

7. Chehval MJ, Purcell MH (1992) Varicocelectomy: incidence of external spermatic vein involvement in the clinical varicocele. Urology 39: 573575

8. Clavijo RI, Carrasquillo R, Ramasamy R (2017) Varicoceles: prevalence and pathogenesis in adult men. Fertil Steril 108(3): 364-369.

9. Cho CL, Esteves SC, Agarwal A (2016) Novel insights into the pathophysiology of varicocele and its association with reactive oxygen species and sperm DNA fragmentation. Asian J Androl 18(2): 186-193.

10. Roque M, Esteves SC (2018) Effect of varicocele repair on sperm DNA fragmentation: a review. Int Urol Nephrol 50(4): 583-603.

11. Goldstein M, Eid JF (1989) Elevation of intratesticular and scrotal skin surface temperature in men with varicocele. J Urol 142(3): 743-745.

12. Wright EJ, Young GP, Goldstein M (1997) Reduction in testicular temperature after varicocelectomy in infertile men. Urology 50(2): 257-259.

13. Tilki D, Kilic E, Tauber R (2007) The complex structure of the smooth muscle layer of spermatic veins and its potential role in the development of varicocele testis. Eur Urol 51(5): 1402-1410.

14. APA Tanrikut, Cigdema B, Mc Quaid, Joseph WA, Goldstein et al. (2011) The impact of varicocele and varicocele repair on serum testosterone. Current Opinion in Obstetrics and Gynecology 23(4): 227-231.

15. P D Kantartzi, Ch D Goulis, G D Goulis, I Papadimas Hippokratia (2007) Male infertility and varicocele: myths and reality 11(3): 99-104.

16. Pasqualotto, Fábio Firmbach (2018) Semen profile, testicular volume, and hormonal levels in infertile patients with varicoceles compared with fertile men with and without varicoceles. Fertility and Sterility 83(1): 74-77.

17. Agarwal Ashok, Sharma Reecha, Harlev Avi, Esteves Sandro C (2016) Effect of varicocele on semen characteristics according to the new 2010 World Health Organization criteria: a systematic review and meta-analysis 18(2): 163-170.

18. Cakiroglu B, Sinanoglu O, Gozukucuk R (2013) The effect of varicocelectomy on sperm parameters in subfertile men with clinical varicoceles who have asthenozoospermia or teratozoospermia with normal sperm density. ISRN Urol 698351.

19. Lawrence Dubin MD, and Richard D Amelar MD (1970) Varicocele size and results of varicoclectomy in selected subfertile men with varicocee. Fert Steril 21(8):606-609.

20. Stahl P, Schlegel PN (2011) Standardization and documentation of varicocele evaluation. Curr Opin Urol 21(6): 500-505.

21. Kohn TP, Ohlander SJ, Jacob JS, Griffin TM, Lipshultz LI, et al. (2015)
The Effect of Subclinical Varicocele on Pregnancy Rates and Semen Parameters: a Systematic Review and Meta-Analysis. Curr 19(7): 53.

22. (2014) Practice Committee of the American Society for Reproductive Medicine; Society for Male Reproduction and Urology. Report on varicocele and infertility: a committee opinion. Fertil Steril 102(6): $1556-1560$.

23. Agarwal A, Deepinder F, Cocuzza M (2007) Efficacy of varicocelectomy in improving semen parameters: new meta-analytical approach. Urology 70(3): 532-538.

24. Haydardedeoglu B, Turunc T, Kilicdag EB, Gul U, Bagis T (2010) The effect of prior varicocelectomy in patients with nonobstructive azoospermia on intracytoplasmic sperm injection outcomes: a retrospective pilot study. Urology 75(1): 83-86.

25. Esteves SC, Miyaoka R, Roque M (2016) Outcome of varicocele repair in men with non-obstructive azoospermia: systematic review and metaanalysis. Asian J Androl 18(2): 246-253.

26. Jacobson DL, Johnson EK (2017) Varicoceles in the pediatric and adolescent population: threat to future fertility?. Fertil Steril 108(3): 370-377.

27. Dane Johnson, Jay Sandlow (2017) Treatment of varicoceles: techniques and outcomes. Fertil Steril 108: 378-384

28. Marcello Cocuzza, Rodrigo Pagani, Rafael Coelho, Miguel Srougi, Jorge Hallak (2010) The systematic use of intraoperative vascular Doppler ultrasound during microsurgical subinguinal varicocelectomy improves precise identification and preservation of testicular blood supply. Fertility and Sterility 93(7): 2396-2399.

29. Abdelrahman SS, Eassa BI (2012) Outcome of loupe-assisted subinguinal varicocelectomy in infertile men. Nephro urology Monthly 4(3): 535-540.

30. Diegidio P, Jhaveri JK, Ghannam S, Pinkhasov R, Shabsigh R et al. (2011) Review of current varicocelectomy techniques and their outcomes. BJU Int 108(7): 1157-1172

31. Wang J, Xia SJ, Liu ZH (2015) Inguinal and subinguinal microvaricocelectomy, the optimal surgical management of varicocele: a meta-analysis. Asian J Androl 17(1):74-80.

32. Ding H, Tian J, Du W, Zhang L, Wang $\mathrm{H}$ et al. (2012) Open nonmicrosurgical, laparoscopic or open microsurgical varicocelectomy for male infertility: a meta-analysis of randomized controlled trials. BJU International 110: 1536-1542.

33. Penson DF, Paltiel AD, Krumholz HM, Palter S (2002) The costeffectiveness of treatment for varicocele related infertility. J Urol 168(6): 2490-2494.

34. Samplaski MK, Lo KC, Grober ED, Zini A, Jarvi KA (2017) Varicocelectomy to "upgrade" semen quality to allow couples to use less invasive forms of assisted reproductive technology. Fertil Steril 108(4): 609-612.

35. Ali Asghar Ketabchi (2015) The Relationship of Varicocele and Mental Health. AASCIT Journal of Medicine 1(4): 53-56. 

(C) Commons Attribution 4.0 License DOI: 10.19080/GJORM.2020.07.5556725

\begin{tabular}{|l|}
\hline \multicolumn{1}{|c|}{ Your next submission with Juniper Publishers } \\
will reach you the below assets \\
- Quality Editorial service \\
- Swift Peer Review \\
- Reprints availability \\
- E-prints Service \\
- Manuscript Podcast for convenient understanding \\
- Global attainment for your research \\
- Manuscript accessibility in different formats \\
( Pdf, E-pub, Full Text, Audio) \\
- Unceasing customer service \\
Track the below URL for one-step submission \\
https://juniperpublishers.com/online-submission.php \\
\hline
\end{tabular}

